\title{
Efficacy of Erythromycin for Postpyloric Placement of Feeding Tubes in Critically Ill Children: A Randomized, Double-Blind, Placebo Controlled Study
}

\author{
Varsha Gharpure, MD; Kathleen L. Meert, MD; and Ashok P. Sarnaik, MD \\ From the Department of Pediatrics, Children's Hospital of Michigan, Wayne State University School of Medicine, Detroit, Michigan
}

\begin{abstract}
Background: Erythromycin enhances gastric emptying and has been suggested to facilitate nasoenteric feeding tube placement in adults. Our primary objective was to evaluate the effect of erythromycin on the transpyloric passage of feeding tubes in critically ill children, and second, to evaluate the effect of erythromycin on the distal migration of duodenal feeding tubes. Methods: Seventy-four children were randomly assigned to receive erythromycin lactobionate $(10 \mathrm{mg} / \mathrm{kg})$ IV or equal volume of saline placebo 60 minutes before passage of a flexible weighted tip feeding tube. Abdominal radiographs were obtained 4 hours later to assess tube placement. If the tube was proximal to the third part of the duodenum, two additional doses of erythromycin/placebo were administered 6 hours apart. Those receiving additional doses had repeat radiographs 14 to 18 hours after tube place-
\end{abstract}

ment. Results: The number of postpyloric feeding tubes was similar in the erythromycin and placebo treated groups 4 hours after tube insertion (23/37 us $27 / 37, p=$ $.5)$. Of those with prepyloric tubes at 4 hours, none in the erythromycin group and 3 in the placebo group had the tube migrate to the postpyloric position by 14 to 18 hours $(p<.05)$. Of those with postpyloric tubes proximal to the third part of the duodenum at 4 hours, additional doses of erythromycin did not cause more tubes to advance further into the intestine than did placebo $(p=.6)$. Conclusions: Erythromycin does not facilitate transpyloric passage of feeding tubes in critically ill children. The distal migration of duodenal tubes further into the small bowel is also not enhanced by erythromycin. (Journal of Parenteral and Enteral Nutrition 25:160-165, 2001)
Nasoenteric feeding tubes are routinely used to provide nutrition to critically ill infants and children. Although the optimal location of the feeding tube within the gastrointestinal tract remains controversial, ${ }^{1-3}$ many clinicians prefer the tube opening to be at or beyond the third part of the duodenum before initiating feedings. Critically ill patients may have antral hypomotility and decreased gastric emptying, especially when treated with sedatives or analgesics such as morphine. ${ }^{3}$ Distal duodenal and jejunal feeding tubes have been associated with higher caloric intakes and lower rates of aspiration pneumonia when compared with gastric tubes. ${ }^{1}$

During the fasting state, cyclic bursts of contractile activity originate in either the stomach or duodenum and propagate distally. ${ }^{4}$ These contractions, known as phase III migrating motor complexes, clear the stomach of indigestible solids. Migrating motor complexes are regulated, at least in part, by the interaction of the intestinal peptide motilin with its receptor. Erythromycin, a macrolide antibiotic, has prokinetic effects on the gastrointestinal tract primarily because of its abil-

Received for publication, May 30, 2000.

Accepted for publication, February 26, 2000.

Correspondence and reprint requests: Kathleen L. Meert, MD, Critical Care Medicine, Children's Hospital of Michigan, 3901 Beaubien Boulevard, Detroit, MI 48201. Electronic mail may be sent to kmeert@med.wayne.edu. ity to act as a motilin agonist. ${ }^{5}$ Erythromycin has been shown to enhance antral activity and accelerate gastric emptying. ${ }^{6,7}$

Recent studies have suggested that erythromycin facilitates the transpyloric placement of enteral feeding tubes in adults. ${ }^{8,9}$ Information regarding the efficacy of erythromycin for feeding tube placement in children is scarce, consisting of only one anecdotal report. ${ }^{10}$ Concern has been expressed regarding the use of erythromycin for tube placement because of potential adverse effects including cardiac dysrhythmias. ${ }^{11-13}$ Our primary objective was to evaluate the effect of erythromycin on the transpyloric passage of feeding tubes in critically ill children, and second, to evaluate the effect of erythromycin on the distal migration of duodenal feeding tubes.

\section{CLINICAL RELEVANCY STATEMENT}

Erythromycin, a macrolide antibiotic, stimulates contractions of the gastric antrum and accelerates gastric emptying. The gastrointestinal prokinetic properties of erythromycin could potentially facilitate the passage of feeding tubes across the gastric pylorus and into the small bowel. However, these prokinetic properties are also responsible for the untoward effects of nausea and vomiting often experienced with use of the drug. Vomiting can lead to aspiration pneumonia, a complication that postpyloric feedings are intended to prevent. We found that erythromycin does not facili- 
tate transpyloric passage of feeding tubes in critically ill children beyond that which can be accomplished by experienced practitioners using a standardized placement technique. The distal migration of duodenal feeding tubes further into the small bowel is also not enhanced by erythromycin. Because of the lack of efficacy and potential for side effects, the use of erythromycin for feeding tube placement is not warranted.

\section{MATERIALS AND METHODS}

All children, age 1 month to 18 years, admitted to the pediatric intensive care unit who required placement of a feeding tube were eligible for the study. In general, feeding tubes were placed in those patients who had a functional gastrointestinal tract but were unable to eat and who were not fasting in preparation for surgery or other procedure. Exclusion criteria were as follows: (1) use of a gastrointestinal prokinetic agent (ie, metoclopramide, cisapride or erythromycin) immediately before or during the current hospital admission, (2) presence of a percutaneous feeding tube, (3) known anatomic obstruction of the gastrointestinal tract, (4) previous esophageal or gastrointestinal surgery, (5) known allergy to erythromycin, (6) use of medications that contraindicate the administration of erythromycin (ie, terfenadine or astemizole), and (7) history of cardiac disease.

Patients were randomly assigned to receive erythromycin lactobionate $(5 \mathrm{mg} / \mathrm{mL}) 10 \mathrm{mg} / \mathrm{kg}$ IV or saline placebo $(2 \mathrm{~mL} / \mathrm{kg})$ IV every 6 hours for up to three doses. Each dose was administered over 30 minutes. A pharmacist not involved in patient care, using a computer-generated table, performed the randomization procedure. Within 30 minutes of infusion of the first dose of erythromycin/placebo, a $6 \mathrm{~F}$ or $8 \mathrm{~F}$ flexible weighted tip feeding tube with a stylet (Kangaroo Enteral Feeding Products, Sherwood Medical, St. Louis, MO) was placed using the technique previously described by Zaloga. ${ }^{14}$ In order to ensure that an appropriate length of tube was passed for the size of the child, three marks were placed on the tube before insertion. ${ }^{15}$ The first mark identified the approximate distance from the nose to the gastroesophageal junction (measured as the distance from the ear to the nose plus the distance from the nose to the xiphoid). The second mark identified the distance from the gastroesophageal junction to the pylorus (measured as the distance from the xiphoid to the right lateral costal margin). A third mark was placed 5 to $10 \mathrm{~cm}$ beyond this length in order to approximate the distance to the distal duodenum or proximal jejunum. The child was placed in the right lateral position with the head of the bed elevated 30 to 45 degrees. The tube with the stylet in place was bent 30 degrees just proximal to its tip and passed through either nostril until the first mark was reached. The tube was rotated while being slowly advanced past the second mark, thereby corkscrewing the weighted tip through the pylorus. Once the resistance of the pylorus was passed, the tube was advanced to the third mark. The color and $\mathrm{pH}$ of the feeding tube aspirate were used to guide placement during insertion. ${ }^{16}$
An abdominal radiograph was obtained to assess tube position 4 hours after tube insertion. A 4-hour interval was chosen in order to allow the study medication time to exert its effect. If the tube opening was proximal to the third part of the duodenum, two additional doses of erythromycin/placebo were administered 6 hours apart, for a total of three doses. If the tube opening reached the third part of the duodenum, no additional doses were given. Those receiving additional erythromycin/placebo had repeat radiographs 14 to 18 hours after tube placement. A pediatric radiologist reviewed each radiograph in order to determine the position of the tube within the gastrointestinal tract. The color and $\mathrm{pH}$ of feeding tube aspirates were also assessed at the time each radiograph was obtained. This information was used to categorize tube placement as prepyloric or postpyloric when the position was uncertain by radiograph. A clear yellow aspirate with $\mathrm{pH} \geq 6$ categorized the tube as postpyloric.

Other data collected included the patient's age, sender, diagnosis, Pediatric Risk of Mortality III (PRISM) ${ }^{17}$ and Therapeutic Intervention Scoring system (TISS) ${ }^{18}$ scores on the day of intensive care unit admission and the day of feeding tube placement, use of mechanical ventilation, medications, and potential side effects of erythromycin. PRISM is an established scoring system consisting of 17 physiologic variables in which the degree of abnormality of each variable is assigned a standard score reflecting the clinical severity of the derangement. TISS consists of approximately 70 variables representing various therapeutic interventions each of which is assigned a standard score based on the complexity and invasiveness of the therapy. Higher PRISM scores indicate a higher degree of physiologic instability and risk of mortality whereas higher TISS scores indicate more therapeutic interventions. Potential side effects of erythromycin were defined as (1) allergic reaction as evidenced by rash or hypotension, (2) ventricular dysrhythmia, (3) vomiting, and (4) loose stool, each occurring within 6 hours of administration of a study medication dose. ${ }^{19}$ Pre-established criteria for early exit from the study included allergic reaction, ventricular dysrhythmia, or more than three episodes of vomiting or loose stool. All patients had continuous electrocardiogram monitoring during the study period. The Wayne State University Human Investigation Committee approved the study. Informed consent was obtained from the parent or legal guardian of all study participants.

\section{Sample Size and Statistical Analysis}

Based on our prior clinical experience using blind feeding tube placement, we estimated that without the use of a prokinetic agent approximately one third of enteral feeding tubes reached a postpyloric position within 4 hours of insertion. An increase to two thirds with the use of a prokinetic agent would represent a clinically meaningful difference. These estimates were similar to published data obtained from adult intensive care unit patients. ${ }^{9}$ To achieve a type I error rate of $5 \%$ and type II error rate of $20 \%$ (power of $80^{c} ;$, with a two-tailed alternative hypothesis. approximately 37 
TABLE I

Clinical characteristics

\begin{tabular}{lcc}
\hline & $\begin{array}{c}\text { Erythromycin } \\
\text { (n = 37) }\end{array}$ & $\begin{array}{c}\text { Placebo } \\
\text { (n=37) }\end{array}$ \\
\hline Age years) & $3.5(0.1-16)^{*}$ & $1.8(0.1-17)$ \\
Male/female & $20 / 17$ & $18 / 19$ \\
PRISM score & $5(0-21)$ & $5(0-25)$ \\
$\quad$ Day of admission & $3(0-12)$ & $2(0-21)$ \\
Day of tube placement & $31(7-50)$ & $31(12-50)$ \\
TISS score & $27(12-43)$ & $26(10-43)$ \\
Day of admission & & \\
Day of tube placement & 15 & 13 \\
Medications (number of patients) & 19 & 25 \\
Morphine & 14 & 12 \\
Benzodiazepines & 3 & 3 \\
Barbiturates & & \\
Paralytic agents & 14 & $24 \dagger$ \\
Diagnoses (number of patients) & 3 & 3 \\
Respiratory failure & 19 & $8 \ddagger$ \\
Sepsis & 1 & 2 \\
Neurologic illness & 28 & $35 \dagger$ \\
Other & & \\
Mechanical ventilation & & \\
$\quad$ (number of patients) & & \\
\hline
\end{tabular}

${ }^{*}$ Median and range, $\dagger p<.05$ and $\ddagger p<.01$ by $\chi^{2}$ test. PRISM, Pediatric Risk of Mortality III; TISS, Therapeutic Intervention Scoring System.

patients were needed in each group (Breeze/STAT version 1.1, GRG Associates, Indianapolis, IN).

Categorical variables are expressed as absolute counts and percentages, and compared between groups using $\chi^{2}$ or Fisher's exacts tests. Ordinal and continuous variables are expressed as medians and ranges, and compared between groups using Mann-Whitney $U$ tests. Continuous data (age) were analyzed as ordinal primarily because of skewed distribution.

\section{RESULTS}

Seventy-four patients were enrolled in the study with 37 randomly assigned to the erythromycin group and 37 to the placebo group. The two groups were similar in age, gender, PRISM and TISS scores, and the number of patients receiving morphine, benzodiazepines, barbiturates, and paralytic agents (Table I).
More erythromycin-treated patients suffered from neurologic illness whereas more placebo-treated patients had respiratory failure. Accordingly, more patients in the placebo group were mechanically ventilated.

Two patients in the erythromycin group exited the study before the 4-hour radiograph (Fig. 1). One patient developed a rash during the study drug infusion and one pulled the tube out just before the radiograph being taken. There was no difference between the erythromycin and placebo groups in the number of postpyloric feeding tubes 4 hours after tube insertion (23 us 27, $p=.5$ ). Categorization of feeding tube position as prepyloric or postpyloric could be accomplished by the 4-hour radiograph alone in 64 cases. Of the remaining 10, 7 had clear yellow aspirates with $\mathrm{pH}$ measurements ranging from 6 to 7.5 , identifying their location as postpyloric.

Of the 22 patients with prepyloric feeding tubes 4 hours after insertion (Fig. 1), none of 12 in the erythromycin group and 3 of 10 in the placebo group had their tube migrate to the first part of the duodenum by 14 to 18 hours $(p<.05)$. One placebo-treated patient with a prepyloric tube at 4 hours pulled the tube out before the 14 to 18 hour radiograph. Overall, 23 of 37 $(62 \%)$ erythromycin-treated patients and 30 of 37 $(81 \%)$ placebo-treated patients had feeding tubes that crossed the pylorus by 14 to 18 hours of insertion $(p=.2)$.

Of the 50 patients with postpyloric tubes 4 hours after insertion (Fig. 2), 17 of 23 erythromycin-treated and 15 of 27 placebo-treated had tubes at or beyond the third part of the duodenum $(p=.3)$. Eighteen patients, 6 erythromycin-treated and 12 placebo-treated, had tubes located within the first or second part of the duodenum. Of these, 1 placebo-treated patient pulled out the feeding tube and exited the study before the 14 to 18 hour radiograph. Only 2 patients in the erythromycin group and 2 in the placebo group had their feeding tubes advance from the first or second part of the duodenum further into the small intestine between the 4-hour and 14 to 18 hour radiograph ( $p=.6$ ). Overall, 19 of $37(51 \%)$ erythromycin-treated patients and 17 of 37 (46\%) placebo-treated patients had feeding

\section{Trans-Pyloric Placement}

Erythromycin

$\mathrm{n}=\mathbf{3 7}$

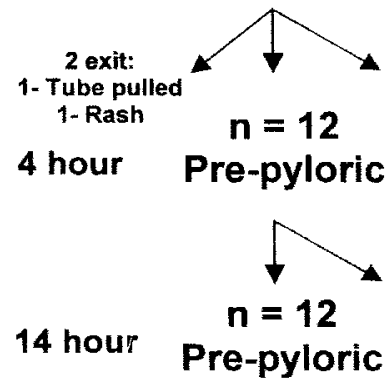

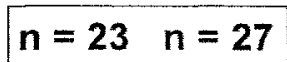

Post-pyloric

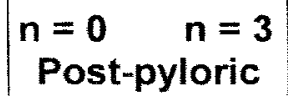

Placebo
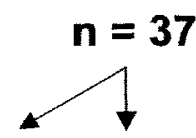

$n=10$

Pre-pyloric

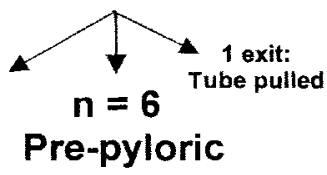

FIG. 1. The numbers of patients achieving transpyloric placement of feeding tubes at 4 hours and 14 to 18 hours after insertion. 


\section{Distal Migration of Post-Pyloric Tubes}
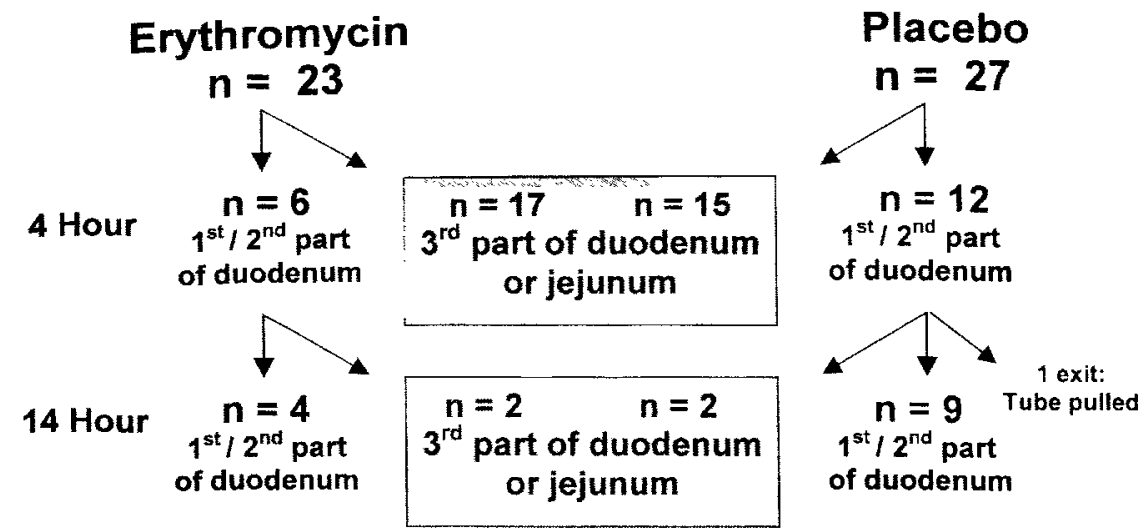

FIG. 2. The numbers of patients with postpyloric tubes that reach the third part of the duodenum or beyond.

tubes at or beyond the third part of the duodenum by 14 to 18 hours of insertion $(p=.8)$.

Potential side effects tended to occur in more patients in the erythromycin group than the placebo group (5 vs 1, $p=.09$ ). Three erythromycin-treated patients experienced vomiting within 6 hours of the infusion, one had a loose stool, and one developed an erythematous rash. One placebo treated patient vomited. No patient developed dysrhythmia or hypotension. No patient had vomiting or loose stool frequent enough to require early exit from the study.

\section{DISCUSSION}

Successful placement of a small bowel feeding tube is often difficult to accomplish at the bedside of a critically ill patient. Published descriptions of small bowel intubation techniques have often included the administration of a gastrointestinal prokinetic agent as an essential component. ${ }^{15,20}$ Whether prokinetic agents increase the likelihood of transpyloric passage of feeding tubes remains controversial. ${ }^{8,9,21-23}$ Randomized controlled trials have shown no benefit of metoclopramide on small bowel intubation rates except in patients with diabetes mellitus. ${ }^{21,22}$ Cisapride has been shown to increase gastric emptying in critically ill, mechanically ventilated patients; however, its ability to facilitate feeding tube placement has not been evaluated. ${ }^{24}$ The recently recognized proarrhythmic effect of cisapride has precluded its routine use. ${ }^{25}$

Our results demonstrated no improvement in small bowel intubation rate with the use of erythromycin. More children in our placebo-treated group achieved transpyloric passage of the feeding tube than anticipated. A post hoc power analysis based on the observed transpyloric passage rates of $62 \%$ and $81 \%$ in the erythromycin-treated and placebo-treated groups, respectively, and a type I error rate of $5 \%$, shows that the null hypothesis of no difference between treatment groups can be accepted with a power of $45 \%$. However, if a type II error was made and the two groups are different, transpyloric passage is actually favored by placebo. The high transpyloric passage rate observed in our study may be due to the use of a standardized technique for feeding tube placement that included the evaluation of aspirate color and $\mathrm{pH}$. In addition, all of our tubes were placed by one of two investigators. Previous studies have suggested that experience with the procedure is one of the most important factors in successful small bowel intubation. ${ }^{22,26}$ Whether erythromycin can improve the rate of transpyloric passage when feeding tubes are placed blindly by less experienced hospital staff cannot be determined from this study. However, erythromycin appears to have little to offer over the use of a standardized technique in experienced hands.

The effect of neurologic illness on gastric emptying and transpyloric passage of feeding tubes remains controversial..$^{9,27-29}$ In one study, mentally compromised patients were found to have higher feeding tube transpyloric passage rates, without the use prokinetic agents, than mentally intact patients..$^{9}$ Other studies have found that patients with neurologic compromise due to head injury tolerate nutrition better when delivered parentally or postpylorically, suggesting that patients with head injuries have delayed gastric emptying. ${ }^{27-29}$ Delayed emptying may impede the passage of feeding tubes across the pylorus. More patients in our erythromycin group had underlying neurologic illness due to a variety of causes. It is unclear whether the distribution of diagnoses within our treatmunt groups had an effect on feeding tube position, independent of erythromycin or placebo.

The prokinetic effects of erythromycin are dose dependent. In healthy volunteers, low doses of erythromycin lactobionate (10 to $50 \mathrm{mg}$ ) IV induce premature phase III migrating motor complexes that originate in the stomach and migrate caudally. ${ }^{30}$ These complexes are similar in duration, frequency, amplitude, and migration velocity to naturally occurring phase III complexes. Higher doses of erythromycin lactobionate ( 200 to $500 \mathrm{mg}$ ) IV induce bursts of strong antral phase III activity that do not propagate to the small bowel and that are followed by prolonged periods of increased antral contractility. ${ }^{6.31}$ These strong 
antral contractions may be responsible for the accelerated gastric emptying observed with erythromycin and also for the untoward effects of nausea and vomiting often experienced with antibacterial dosages. ${ }^{6,7}$ In our study, erythromycin was administered to children at a dose of $10 \mathrm{mg} / \mathrm{kg}$ of body weight. Two previous studies conducted in adults used relatively lower doses of erythromycin indexed to body weight. ${ }^{8,9}$ Both adult studies found erythromycin to be effective in facilitating transpyloric passage of feeding tubes. Whether lower doses of erythromycin would facilitate the transpyloric passage of feeding tubes in critically ill children requires further investigation.

In our patients, no statistically significant effect of erythromycin on the distal migration of duodenal feeding tubes was observed. However, more children in the erythromycin group had feeding tubes that reached the third part of the duodenum or beyond. A post hoc power analysis based on the observed rates of $51 \%$ and $46 \%$ in the erythromycin and placebo treated groups, respectively, and a type I error rate of 5\%, reveals a power of $7 \%$. The possibility of a type II error concerning the effect of erythromycin on distal migration of duodenal feeding tubes exists. However, to demonstrate a difference between treatment groups of this magnitude, with power of $80 \%, 1500$ patients in each group would be required.

Serious side effects of erythromycin include the development of prolonged QT syndrome, premature ventricular contractions, and polymorphic ventricular tachycardia. ${ }^{12,13}$ Although rare, tachydysrhythmias have been associated with the IV administration of erythromycin and are most likely related to serum levels of the drug. Although QT intervals were not measured before and after administration of erythromycin in our study patients, none developed an obvious dysrhythmia associated with erythromycin use. Children with a past or present diagnosis of cardiac disease were excluded from our study because of their potential increased risk for developing a drug-induced dysrhythmia. Three of our erythromycin-treated children experienced vomiting in temporal association with the drug. Although not usually considered a serious side effect, vomiting can lead to aspiration pneumonia, the complication that postpyloric feedings are intended to prevent. As with any therapeutic modality, the risks and benefits of erythromycin for feeding tube placement must be considered before its routine use.

In summary, our findings suggest that erythromycin does not facilitate transpyloric passage of feeding tubes in critically ill children. The distal migration of postpyloric feeding tubes further into the small bowel is also not enhanced by erythromycin. Because of the lack of efficacy and potential for side effects, the use of erythromycin for feeding tube placement is not warranted.

\section{ACKNOWLEDGMENTS}

The study was supported by a grant from the Children's Research Center of Michigan. Ronald Thomas, $\mathrm{PhD}$, Children's Research Center of Michigan was consulted for statistical review.

\section{REFERENCES}

1. Montecalvo MA, Steger KA, Farber HW, et al: Nutritional outcome and pneumonia in critical care patients randomized to gastric vs jejunal tube feedings. Crit Care Med 20:1377-1387, 1992

2. Strong RM, Condon SC, Solinger MR, et al: Equal aspiration rates from postpylorus and intragastric-placed small-bore nasoenteric feeding tubes: A randomized prospective study. JPEN 16:59-63, 1992

3. Bosscha K, Nieuwenhuijs VB, Vos A, et al: Gastrointestinal motility and gastric tube feeding in mechanically ventilated patients. Crit Care Med 26:1510-1517, 1998

4. Christensen J: Intestinal motor physiology. IN Sleisenger and Fordtran's Gastrointestinal and Liver Disease. Pathophysiology/ Diagnosis/Management, 6th ed. Feldman M, Scharschmidt BF, Sleisenger MH, Klein S (eds). WB Sanders Company, Philadelphia, 1998, pp 1437-1450

5. Weber FH, Richards RD, McCallum RW: Erythromycin: A motilin agonist and gastro-intestinal prokinetic agent. Am J Gastroenterol 88:485-490, 1993

6. Sarna SK, Soergel KH, Koch TR, et al: Gastrointestinal motor effects of erythromycin in humans. Gastroenterology 101:14881496, 1991

7. Dive A, Miesse C, Galanti L, et al: Effect of erythromycin on gastric motility in mechanically ventilated critically ill patients: A double-blind, randomized, placebo-controlled study. Crit Care Med 23:1356-1362, 1995

8. Stern MA, Wolf DC: Erythromycin as a prokinetic agent: A prospective, randomized, controlled study of efficacy in nasoenteric tube placement. Am J Gastroenterol 89:2011-2013, 1994

9. Kalliafas S, Choban PS, Ziegler D, et al: Erythromycin facilitates postpyloric placement of nasoduodenal feeding tubes in intensive care unit patients: Randomized, double-blinded, placebo-controlled trial. JPEN 20:385-388, 1996

10. Di Lorenzo C, Lachman R, Hyman PE: Intravenous erythromycin for postpyloric intubation. J Pediatr Gastroenterol Nutr 11:45-47, 1990

11. Gouyon JB: The use of erythromycin lactobionate to facilitate the postpyloric passage of tubes in children. J Pediatr Gastroenterol Nutr 14:120, 1992

12. Farrar HC, Walsh-Sukys MC, Kyllonen K, et al: Cardiac toxicity associated with intravenous erythromycin lactobionate: Two case reports and a review of the literature. Pediatr Infect Dis J 12:688-691, 1993

13. Drici MD, Knollmann BC, Wang WX, et al: Cardiac actions of erythromycin: Influence of female sex. JAMA 280:1774-1776, 1998

14. Zaloga GP: Bedside method for placing small bowel feeding tubes in critically ill patients. A prospective study. Chest 100:16431646,1991

15. Chellis MJ, Sanders SV, Dean JM, et al: Bedside transpyloric tube placement in the pediatric intensive care unit. JPEN $20: 88-90,1996$

16. Gharpure V, Meert, KL, Sarnaik AP: Indicators of post-pyloric feeding tube placement in children. Crit Care Med 28:29622966,2000

17. Pollack MM, Patel KM, Ruttimann UE: PRISM III: An updated pediatric risk of mortality score. Crit Care Med 24:743-752, 1996

18. Keene AR, Cullen DJ: Therapeutic intervention scoring systems: Update 1983. Crit Care Med 11:1-3, 1983

19. Kapusnik-Uner JE, Sande MA, Chambers HF: Antimicrobial agents: Tetracyclines, chloramphenicol, erythromycin and others. IN Goodman and Gilman's The Pharmacological Basis of Therapeutics, 9th ed. Hardman JG, Limbird LE, Molinoff PB, Ruddon RW (eds). McGraw-Hill, New York, 1996, pp 1123-1153

20. Lord LM, Weiser-Maimone A, Pulhamus M, et al: Comparison of weighted vs unweighted enteral feeding tubes for effecacy of transpyloric intubation. JPEN 17:271-273, 1993

21. Kittinger JW, Sandler RS, Heizer WD: Efficacy of metoclopramide as an adjunct to duodenal placement of small-bore feeding tubes: A randomized, placebo-controlled, double-blind study. JPEN 11:33-37, 1987

22. Heiselman DE, Hofer T, Vidovich RR: Enteral feeding tube placement success with intravenous metoclopramide administration in ICU patients. Chest 107:1686-1688,1995 
23. Paz HL, Weinar M, Sherman MS: Motility agents for the placement of weighted and unweighted feeding tubes in critically ill patients. Intensive Care Med 22:301-314, 1996

24. Spapen HD, Duinslaeger L, Diltoer M, et al: Gastric emptying in critically ill patients is accelerated by adding cisapride to a standard enteral feeding protocol: Results of a prospective, randomized, controlled trial. Crit Care Med 23:481485, 1995

25. Hill SL, Evangelista JK, Pizzi AM, et al: Proarrhythmia associated with cisapride in children. Pediatrics 101:10531056,1998

26. Matz ME, Leib MS, Monroe WE, et al: Evaluation of atropine, glucagon, and metoclopramide for facilitation of endoscopic intubation of the duodenum in dogs. Am $J$ Vet Res $53: 261,1992$
27. Rapp RP, Young B, Twyman D. et al: The favorable effect of early parenteral feeding on survival in head-injured patient. J Neurosurg 58:906-912. 1983

28. Young B, Ott L, Twyman D, et al: The effect of nutritional support on outcome from severe head injury. J Neurosurg $67: 668-676,1987$

29. Grahm TW, Zadrozny DB, Harrington T: The benefits of early jejunal hyperalimentation in the head-injured patient. Neurosurgery 25:729-735, 1989

30. Tomomasa T, Kuroume T, Arai H. et al: Erythromycin induces migrating motor complex in human gastrointestinal tract. Dig Dis Sci 31:157-161, 1986

31. Tack J, Janssens J, Vantrappen G, et al: Effect of erythromycin on gastric motility in controls and in diabetic gastroparesis. Gastroenterology 103:72-79, 1992 